\section{(1) bsertoutions}

\author{
ON THE
}

\section{ACTION AND USES OF THE EUSTACHIAN TUBE, AND THE TREATMENT OF ITS DISEASES.}

BY

JOSEPH TOYNBEE, F.R.S., F.R.C.S..,

AURII, SURGEON TO ST. IARY'S HOSPITAI; CONSULTING AURAL SURGEOY TO THE ASYLUM FOR THE DFAF AND DUMP.

\section{I.-Physiological and ANatomical Observations.}

IT is well known that the distinguished anatomist Eustachius, in the sixteenth century, discovered the tube of communication between the cavity of the fauces and that of the tympanum; and since this discovery the tube has been named after Eustachius. It is, however, remarkable, that Eustachius, when he gave an account of his discovery to the world, fell into the grave error of describing the Eustachian tube as being constantly open; thus considering that the air in the fauces was always continuous with that in the cavity of the tympanum. It is still more remarkable that succeeding physiologists, adopting this error of Eustachius, brought forward arguments or experiments to prove that, for the purpose of efficient hearing, it is absolutely essential for the faucial air to be always continuous with the tympanic air. Thus, Haller writes :-

"Auricula non unica via est, per quam soni ad tympanum veniunt, est et altera, per nares, et os et Eustachii tubam, semper patula. Certum est hominem, qui naturali instinctu regitur, quoties accuratiùs vult sonos percipere, os latè aperire, indecoro gestu et rustico, sed ad finem suum non inutili, potissimum in is qui graviùs audiunt. Eum sonum videtur in tympano, per reHexiones et repetitiones confirmari." (Elementa Physiologice Corporis Humani. Lausannæ: 1763. P'.285.)

I will also quote the opinion of two or three modern physiologists. Thus, Müller considers the object of the Eustachian tube being open is :-

"That a certain degree of dulness which the sound might acquire from the resonance of the apparatus is avoided."

Müller gives the result of several experiments with an apparatus to represent the open Eustachian tube, and adds that

"The most certain method of ascertaining the function of the Eustachian tube would, undoubtedly, be to close the Eustachian itself artificially; but in such a way that the pressure of the air in the tympanum should not thereby be increased, and greater tension of the membrana tympani produced. But this is scarcely possible." Henle "supposes that the air of the cavity of the mouth and nose are, in like manner, enabled, through the medium of the Eustachian tube, to increase by resonance the intensity of sounds entering the ear through the external meatus." (Müller's Physiology, translated by Baly, vol. ii, pp. $12 \pi(1$ and 1:22.)

Dr. Todd speaks of one object of the Eustachian tube being "to afford an outlet for the escape of such sonorous undulations as do not impinge upon the labyrinthine walls of the tympanum." (Cisclopadia of Anatomy and Physiology; article Hearing, p. 576. 1841.)

Thus, from the time of Eustachius to that of Dr.
Todd, no anatomist or physiologist seems to have. entertained any other opinion regarding the Eustachian tube than that it is constantly open. In the year 1841, Mr. Wharton Jones, in speaking of the Eustachian tube, says :

"In the state of rest, its outer and inner walls lie in contact. By this arrangement the tube is as if provided with a valve opening both ways, but so weak as to be readily forced by the breath and by the action of the surrounding peristaphyline muscles." (Cyclopadia of Surgery, part ix, p. 21.)

Further on, Mr. Jones writes :-

"It is to be remarked that the Eustachian tube is not habitually wide open, so that the air can blow freely in and out; but that, on the contrary, in the state of rest, its walls lie collapsed. By this arrangement, which gives to the Eustachian tube the properties of a sort of weak valve opening either way, the too ready course of the air is opposed." (Loc. cit., p. 2:3.)

Mr. Wharton Jones here speaking "of the tube as not habitually rcide open," and of the Eustachian tube being a valve "so weak as to be readily forced by the breath," by no means left it to be inferred that for the purpose of hearing the Eustachian tube is closed. At least, those physiologists who wrote subsequently to the publication of Mr. W. Jones's observations did not draw the inference that for the purposes of hearing the tympanum ought to be a closed cavity. Thus Dr. Carpenter, four years after Mr. Jones's paper was published, writes as follows :-

"The common idea is, that it (the Eustachian tube) serves the same purpose with the hole in the ordinary drum; the effect of which is generally supposed to be the removal of all impediment to the vibrations of the membrane that would be offered by the complete inclosure of the air within." (Principles of Human Physiology, 3rd edit. 1846, p. 427).

It may also be remarked, that Hyrtl, in the year previous to the publication of the third edition of Dr. Carpenter's Human Physiology, expressed an opinion somewhat similar to that advocated by $\mathrm{Mr}$. Jones. 'Thus, he writes :-

"The walls of the convoluted trumpet are disposed to lie upon each other and form mucous adhesions, so that, as one may easily satisfy himself, a considerable derree of compression of the air in the mouth and nose (by means of the muscles of the cheek, the mouth being shut) is necessary to force air into the cavitas tympani." (Vergleichende Anatomie über das innere Gehörorgan des Menschen und der Saugthiere, 1845, p. 51).

From the above statements by Mr. W. Jones and by Hyrtl, the true action of the Eustachian tube was by no means indicated, as will, I think, be apparent from the perusal of the following observations. In the year 1852, I laid a paper before the Royal Society, entitled, "On the Functions of the Membrana Tympani, the Ossicles and Muscles of the Tympanum, and of the Eustachian Tube, in the Human Ear; with an Account of the Muscles of the Eustachian Tube, and their Action in Different Classes of Animals." The conclusions arrived at in that paper are the following :

1. That the faucial orifices of the Eustachian tubes are closed, and the tympanic cavities do not communicate with the cavity of the fauces, excepting during certain muscular actions.

2. In man, and some other mammalia, the Eustachian tubes are opened momentarily during 
- the act of swallowing by the muscles of the palate; in other animals they are opened by the superior constrictor of pharynx.

3. In birds there is a membranous tube common to the two osseous Eustachian tubes, and this membranous tube is opened by the action of the internal pterygoid muscles.

4. For the function of hearing to be perfect, it is requisite that the tympanic cavity should be closed from the outer air.

That the faucial orifices of the Eustachian tubes are really closed, and that there is no communication between the air in the cavity of the tympanum and that in the fauces except during certain muscular movements, can be easily proved by very simple experiments.

Thus, if the mouth and nose be closed during the act of swallowing, a sensation of pressure is produced in the ears. This arises from the air being partly withdrawn from the tympanic cavity by the action of the faucial muscles during the act of deglutition; and thus the outer surface of the membrana tympani, pressed upon by the superincumbent atmosphere, and not being duly supported internally, is pressed inwards, and the sense of weight produced. If the mouth and nose be then opened, and the act of respiration be performed, the sensation of pressure in the ears nevertheless remains; and it disappears only when the act of swallowing is practised with open nostrils or mouth; this act of swallowing opening the Eustachian tube, and thus permitting air to enter the tympanic cavity, and to replace that which had been withdrawn during the act of swallowing with closed nostrils and mouth. It may be observed that the act of swallowing can, on no occasion, be performed without the production of a slight sensation in each ear ; and this sensation is now recognised to be the result of the act of opening of the Eustachian tubes by the faucial muscles. That the act of deglutition is the one whereby the orifices of the Eustachian tubes are opened, and that, as a rule, they are not opened without the performance of this act, may also be inferred from what takes place in the ears during a descent in the diving-bell. It is well known to persons who have performed this operation, that as the bell descends under water, a sensation of great pressure is felt in the ears, and that this sensation, if not relieved, often advances to one of pain. Those accustorned to descend in the diving-bell, are aware that this unpleasant sensation of pressure can be averted, or, if produced, can be removed by the performance of the act of swallowing; the rationale of this proceeding is that, during the descent of the diving-bell, the compressed air in the bell exercises great pressure on the outer surface of the drums of the ears, their inner surface being inefficiently supported by the air in the tympanic cavity, which is much more rarified than that without. On the act of swallowing being performed, the Eustachian tubes open, and the condensed air enters the tympanic cavities, and thus, by supporting the inner surface of the drum by a pressure equal to that on its outer surface the feeling of weight is removed. An experiment of a character analogous to the last is often performed on the rapid descent of a mountain. In the ascent, rarefied air, during the act of swallowing saliva, enters the tympanic cavities; and on the descent, the act of swallowing requires to be frequently performed, in order that the Eustachian tubes be opened, denser air introduced, and a constantly recurring sense of pressure removed. Another simple experiment may be referred to, the performance of which also illustrates the closed condition of the Eustachian tube except during the momentary act of swallowing. Let the nostrils be held closed by the finger and thumb, and let air, by a forced attempt at expiration which distends the nares, be blown into each tympanic cavity. A sensation of pressure is produced in each ear, which remains during repeated acts of respiration; but which disappears upon the performance of the act of deglutition, whereby the Eustachian tubes are opened. In the first place, it is obvious that the Eustachian tube should permit of being opened, and that it should be frequently opened (as it is during the process of swallowing saliva which is always going on), in order that the air, the density of which is unceasingly changing, may be of the same specific gravity on the inside as on the outside of the drum; were it not so, the drum would be forcibly pressed inwards or outwards, according to circumstances already alluded to, and its free vibrations impeded. It is also requisite for the Eustachian tube to be frequently open, in order that mucus constantly secreted in the tympanic cavity may escape into the fauces.

There are, nevertheless, certain reasons so manifest why the Eustachian tubes should be closed except during the act of swallowing, and why the air in the tympanic cavities should not be continuous with that in the mouth and nares, that it appears remarkable how contrary opinions should have taken origin and have been maintained during so many years.

In the first place, it is necessary for the Eustachian tubes to be ordinarily closed, that is to say, closed while the function of hearing is being performed, in order that the sound arising from the acts of respiration, deglutition, mastication, and articulation, may not enter the tympanic cavities through the Eustachian tubes. This fact was first pointed out, and specially insisted upon by Dr. Jago, who suffers at times from the effects of a patent tube, and whose words I will quote. He says :-

"I will detail the sonorous phenomena that are created by an open Eustachian tube. At each elevation and depression of the ribs, particularly in the latter act, the rippling of the air upon the rim of reflection of the lining membrane of the throat into this tube, expresses itself by a soufle like that from blowing into a bottle. Also, as air expelled from the chest is split at the sof palate into its three streams from the commencing border of the nearer of the posterior nares, waves run into the drum, and give utterance to a harsher souffle or bruit. Müller, whilst relating the aural effects that arose from the, to him, unknown (the prevalent idea of a permanently expanded tube precluded him from all chance of perceiving these things aright) modifications produced in his own ears by muscular effort, uses this language: The sound of one's own voice by this means acquires the intensity of the tones of an organ. I can testify that is not mere flourish; and if there be here no exaggeration, what illustration would he have found could he have tried, under such conditions, the utmost strain of voice, as in the act of shouting; or had he been seized with violent sneezing or coughing? I will do my best further to oharacterise the acoustic phenomena consequent upon an open Eustachian tube. If another person puts his lips close to our ear, and speaks, 
not to say shouts, right into the external meatus, we all know how great a shock is produced. Such effects are of the same kind as those from speaking into one's own ear through its Eustachian tube..... l, et any one meditate upon the foregoing sum of evils, and he will own what a happy correlation it is that the glottis and guttural extremity of the Eustachian tube should never be open together; so that when the latter is subservient to the tympanum, we cannot speak, sing, cough, sneeze, nor sigh, sob, or whoop." (Eustachian Tube, why Opened in Deglutition. By James Jago, A.B.Cantab., M.B.Oxon. J. Churchill. 1856.)

The statement just quoted from Dr. Jago finds confirmation in the experiments by Müller alluded to in the foregoing paragraph; and it is in no small degree remarkable that, in face of all his experiments, Müller should never have uttered a suspicion that the commonly received opinion regarding the patent state of the Eustachian tube was incorrect. And yet the single fact cited by him from Schellhammer ought to have shown him that the Eustachian tube, under ordinary circumstances, cannot be open. Thus, Schellhammer

"Introduced a vibrating tuning fork into the interior of the mouth, and found that its sound was, in that situation, scarcely heard. Held in front of the mouth moderately open, it sounds very loudly..... The ticking of a watch also held in the mouth in such a manner that it does not touch the teeth or tongue is scarcely beard."

Müller having arrived at the conclusion that as the sound of a speaking voice, etc., is not heard from within, i.e., through the agency of the Eustachian tubes, also arrived at the singular conclusion that the drum of the ear could not be made to vibrate by undulations impinging upon its inner surface, and it never occurred to him to conceive that sounds do not travel from the mouth, nares, and fauces, to the tympanic cavities through the Eustachian tubes, because the Eustachian tubes are ordinarily closed.

But as I have stated there is a second reason why the Eustachian tubes should be closed in addition to the necessity of the exclusion of the sounds from the mouth and fauces. It is full well known that there are two pathways for the passage of sound from the membrana tympani to the nervous apparatus; one being the chain of ossicles from the membrana tympani to the vestibule; the other being the air from the membrana tympani to the membrana fenestra rotunda. Now, if the sonorous undulations in the tympanic cavity destined to impress the membrana fenestræ rotundx be allowed to escape from the tympanic cavity through the Eustachian tube into the fauces, it necessarily follows that the membrana fenestræ rotundæ will receive fewer of these vibrations than if they had been confined to the tvinpanum. Dr. Jago doubts if any deterioration of hearing results from the patent state of the Eustachian tube; but after repeated observations, I have been confirmed in the conclusion that any cause interfering with the impingement of the vibrations upon the membrane of the fenestra rotunda, whether it be a patent condition of the Eustachian tube, or a thickened state of the mucous membrane lining the tympanum, sensibly deteriorates the function of hearing, and such deterioration is made manifest by the use of some well recognised test.

It may, however, be observed that, whether the main object of the Eustachian tube being closed, except during the momentary act of deglutition, is to prevent the passage of sounds from the mouth and fauces to the tympanic cavity, or whether it is to confine the sonorous undulations to the tympanic cavity, the fact of the tube being so closed, except during the action above indicated, is now undoubted, and generally accepted by physiologists; and it is manifest that the two functions of the Eustachian tube-the allowance of an egress of mucus from the tympanic cavity, and the ingress or egress of air so as to insure an equal degree of density for the air inside, and for that outside the drum-can be adequately performed by the Eustachian tube being opened at intervals, and only for a moment.

The means by which the Eustachian tube is opened are two muscles of the palate, the tensor and levator palati.

The tensor, also called the circumflexus palati muscle, arises by means of tendinous fibres in the scaphoid fossa of the sphenoid bone, from the anterior and external surface of the fibro-cartilage of the Eustachian tube, and from the adjacent surface of the great wing of the sphenoid. Hence it descends along the posterior border of the internal ring of the sphenoid bone, winds round the hamular process, assumes an horizontal direction, and is inserted into the velum of the palate. One action of this muscle, doubtless, is to draw tense the soft palate; but a second action is to open the Eustachian tube. This action is effected by the contraction of the muscle when the veil of the palate is fixed; if this action of this muscle be imitated by drawing the fibres towards the palate, the outer wall of the Eustachian tube will be found to be drawn in an anterior and external direction apart from the inner wall. Haller was of opinion that the action of this muscle was to dilate the Eustachian tube ; and had he been aware that the tube is not naturally open, he would, doubtless, have described it as opening the tube. Haller's words are :-

"Mihi, cui cartilago inferiorem partem tubæ tenet, eam a musculo secundum hamulum pterygoideum circumflexo probabile tit dilatari." (Opus cit., p. 226.)

The levator palati muscle arises by short fibres from the inferior surface of the petrous bone, in front of the outer opening of the canalis caroticus, and from the adjacent portion of the fibro-cartilage of the Eustachian tube. It descends obliquely, posteriorly, and internally, and expands in the soft palate.

[To be continued.]

Chioride of Lime as an Insecticine. In scattering chloride of lime on a plank in a stable, all kinds of flies, but more especially biting flies, were quickly got rid of. Sprinkling beds of vegetables with even a weak solution of this salt, effectually preserves them from the attacks of caterpillars, buttertlies, mordella, sligs, etc. It has the same effect when sprinkled on the foliage of fruit trees. A paste of one part of powdered chloride of lime and one-half part of some fatty matter, placed in a narrow band round the trunk of the tree, prevents insects from creeping up it. It has even been noticed that rats and mice quit places in which a certain quantity of chloride of lime has been spread. This salt, dried and finely powdered, can, no doubt, be employed for the same purposes as flour of sulphur, and be spread by the same means. (Dingler's Polytechnisches Journal, clxi, 240.) 